\title{
O RETRATO EM RUÍNAS E O CORPO QUE NOS OLHA
}

\section{THE RUINED PORTRAIT AND THE BODY THAT LOOKS AT US}

FILOMENA SERRA ${ }^{1 *}$

fil.serra@fcsh.unl.pt

Este artigo discute a pintura Olympia de Édouard Manet e a cópia pintada por Guilherme de Santa-Rita, apresentada na exposição da Academia de Belas-Artes, inaugurada em 18 de Março de 1911, entendendo que esse trabalho deve ocupar um lugar significativo na historiografia da arte em Portugal, sobretudo para a história do modernismo português nas artes plásticas. $\mathrm{O}$ artigo destaca a recepção dessa cópia apresentada naquela exposição, precisamente no dia anterior à Exposição Livre de 1911.

A Olympia de Santa-Rita, hoje lamentavelmente esquecida, questionou a pintura e o género do retrato em Portugal, a sua relação com o corpo logo no início do século, quando não toda a hipocrisia de uma sociedade. Relembrá-la é fundamental para a história da arte do retrato em Portugal.

Palavras-Chave: retrato; corpo; pintura; Olympia; Santa Rita Pintor; Manet.

This article discusses Olympia, the painting by Édouard Manet, and its copy by Guilherme de Santa-Rita presented at the Academia de Belas-Artes exhibition inaugurated the 18th of March, 1911. I believe that Santa-Rita's painting must occupy a significant place in art historiography in Portugal, namely the history of Portuguese modernism. The article emphasizes the reception of Olympia's copy presented precisely the day before the 1911 Free Exhibition.

Santa-Rita's copy, regrettably forgotten nowadays, questioned Portuguese painting and the portrait genre in particular, namely their relation with human body at the beginning of the 20th century, as well as the overwhelming hypocrisy of the whole society. To remember this painting is essential for the history of portrait art in Portugal.

Keywords: portrait; body; painting; Olympia; Santa-Rita Pintor; Manet.

DOI: https://doi.org/10.21814/2i.2434

1* Investigadora doutorada, Universidade Nova de Lisboa, Faculdade de Ciências Sociais e Humanas, Instituto de História da Arte — Núcleo de Estudos de Arte Contemporânea, Lisboa, Portugal. 


\section{Introdução}

Na História da Arte moderna portuguesa, Guilherme de Santa-Rita, ou Santa-Rita Pintor, apresenta uma imagem frequentemente negativa, assinalando-se a atitude de blagueur e de mistificador genial, um dandy ou shandy e "artista sem obra" (Jouannais, 2009, pp.1718), cujo comportamento sugere não ter de prestar provas das suas capacidades como pintor. Dele ficaria a memória do brilhante provocador, do burguês, cuja vida se condensou numa espécie de deriva. O lugar que este artista ocupa na arte e cultura em Portugal materializa-se em fragmentos, através de escassas obras, algumas reproduzidas no número dois da revista Orpheu em 1915 e na revista Portugal Futurista de que foi o mentor. Na hora da morte, o pintor teria pedido à família que destruísse tudo o que realizara. Subsistem ainda pinturas como Louco ou Orpheu nos Infernos, alguns desenhos e caricaturas e, principalmente, trabalhos escolares.

Santa-Rita, na historiografia da arte em Portugal, tornou-se, assim, uma figura quase mítica, diremos mesmo invisível, embora presente através de Portugal Futurista e numa memória partilhada com outros pintores e criadores da sua geração, como foi o caso de José de Almada Negreiros, que afirmaria ter cortado relações pessoais com quem inventava "histórias estropiadas" sobre o pintor e para quem Santa-Rita ficaria como "um dos mais extraordinários espíritos" de "genial coerência" que conheceu em toda a sua vida (Negreiros, 1965, p. 9). O pintor também exerceria uma influência determinante noutros poetas e artistas seus contemporâneos, como Mário de Sá-Carneiro ou Manuel Jardim (1884-1923), um pouco mais velho, de quem foi amigo e com quem partilhou a sua admiração pelo pintor Édouard Manet (1832-1883).

Ora, um dos primeiros momentos no século XX, em Portugal, em que se repensa o retrato convencional mas também o nu idealizado, na sua forma clássica, é feito com uma cópia de uma pintura europeia do século XIX, a pintura Olympia de 1863, daquele pintor francês que Guilherme de Santa-Rita realizou em Paris enquanto aluno pensionista, entre meados de 1910 e princípios de 1911, e que foi apresentada na Exposição da Academia de Belas em 19 de Março deste último ano.

$\mathrm{O}$ facto em si nada tem de extraordinário, a não ser que essa pintura é unanimemente apontada como o marco sinalizador e ponto de partida da arte moderna europeia. Se pensarmos que no dia anterior também um grupo de jovens se afirmava contra o academismo proclamando que queriam ser Livres, concluímos que estamos num momento de mudança e, como veremos, de confronto estético entre dois mundos no modo de olhar a pintura, o género do retrato e a arte em geral. Sendo pretexto de interrogação da pintura e, mais do que isso, de ataque às categorias estéticas tradicionais, outros artistas reexaminariam este grande ícone da história da arte durante todo o século XX.

Este artigo discute a pintura Olympia de Édouard Manet e a cópia pintada por Guilherme de Santa-Rita, hoje na Academia de Belas Artes de Lisboa, entendendo que esse trabalho, actualmente esquecido, tem o seu lugar na história e na historiografia da arte em Portugal. A pintura foi apresentada na exposição daquela instituição, em 18 de Março de 1912. No dia anterior, a Exposição dos "Livres", através da caricatura e do humor (França, 1991, pp. 37-38), também questionava a pintura e o género do retrato. O artigo destaca, ainda, a recepção à cópia de Olympia por parte da crítica lisboeta e compara a recepção da mesma no século XIX, sublinhando a sua importância para a história do retrato, para um novo regime da imagem e a relação do retrato com o corpo. 


\section{A Exposição da Academia de Belas-Artes e a Exposição Livre, em 18 e 19 Março de 1911}

Sob os auspícios da nova República Portuguesa abria, no dia 19 de Março de 1911 a Exposição da Academia de Belas-Artes de Lisboa. No dia anterior no salão de exposições do fotógrafo Bobone, na Rua Serpa Pinto, realizara-se uma outra - a Exposição dos Livres - onde se apresentavam oito jovens estudantes que, à margem do ensino oficial português, frequentavam em Paris as Academias Livres e tentavam a carreira das artes.

É importante sublinhar que este momento e este grupo são habitualmente designados como o início do modernismo nas artes plásticas (França, 1991, pp. 37-38). Por essa razão, será necessário sublinhar a quase coincidência cronológica das duas exposições e quem são os expositores.

De facto, os "Livres", que incluíam Eduardo Viana (1881-1967), Emmerico Nunes (1888-1968), Francis Smith (1881-1961), Manuel Bentes (1885-1961) e Manuel Jardim (1884-1923), entre outros (França, 1974, p. 22), não se sentiam coagidos pela imposição de regras da Academia ao realizarem a sua exposição e, nesse sentido, eram livres. Contrariamente, os pensionistas do Estado (que em breve, com a nova reforma, se viriam a apelidar de bolseiros) estavam condicionados a uma disciplina que os obrigava a apresentar dentro do género a que tinham concorrido anualmente estudos de pintura e escultura, quando não cópias, feitos a partir dos originais dos mestres existentes nas galerias dos Museus do Luxemburgo e do Louvre.

Assim, na Exposição da Academia, os pensionistas expunham conjuntamente com os finalistas dos Cursos Gerais de Pintura e Escultura desse ano, eles próprios candidatos às bolsas para Paris. Por conseguinte, os trabalhos enviados pelos primeiros deviam constituir um exemplo que cimentava esse posicionamento estético de uma aprendizagem que na capital das artes se supunha ser continuada e aprofundada. A temática que era cultivada como um ideal didáctico de inspiração democrática e nacionalista era a Pintura de História, embora a paisagem e as representações animalistas pudessem ali mostrar-se em grande número. Mas também se encontravam representações da figura do nu, pastiches de formas clássicas. Quanto ao retrato, parecia viver das imagens imaginadas e imaginárias das personagens míticas e bíblicas que povoavam a pintura de história ou de costumes.

Nesse ano, porém, um dos quadros enviados pelo jovem pensionista Guilherme de Santa-Rita parecia não seguir essa estrita linha académica. O jovem havia escolhido como trabalho, a ser avaliado, uma cópia de Olympia, uma pintura que fizera grande escândalo no Salon parisiense de 1865 , havia quarenta e seis anos.

Nessa época, uma exposição da Academia era sempre aguardada com expectativa, sobretudo quando alguém como o historiador e crítico de arte José de Figueiredo (18721937) sobre ela escrevia. A recepção da exposição parece ter-se restringido a um campo bem definido e a sua menção explícita foi expressamente referida pelas críticas daquele historiador e de um jornalista, Higino de Mendonça. O facto é que essa exposição marcaria certamente senão a carreira do pintor, pelo menos a sua reputação. Lembremos que, em finais de 1912, o regime republicano por acção do ministro João Chagas retira a Santa-Rita (e a outros pintores) a bolsa que anteriormente ganhara por concurso, facto pouco claro e nunca explicado. Consequentemente, o estudante perderia a possibilidade de continuar a concorrer à École des Beaux-Arts, a cuja admissão reprovara em Maio desse ano. Talvez esse acontecimento tivesse tido alguma influência na posterior destruição da obra e o consequente maior ou menor esquecimento a que injustamente o artista tem sido votado. 
A verdade é que entre 1911 e 1912 o pintor começa a frequentar os meios vanguardistas parisienses e se aproxima do Futurismo. Em Fevereiro de 1912, expõe no Salon des Indépendents a pintura $O$ Ruído num quarto sem Móveis, anunciada sarcasticamente na revista Teatro (Freitas, 1913, p. 4).

\section{José de Figueiredo e a crítica à Olympia de Santa-Rita}

Logo no dia 25 de Março de 1911 saíram duas notícias nos jornais República e Novidades. Tendo a primazia da crítica no novo jornal do jovem regime, José de Figueiredo, em breve futuro director do Museu de Arte Antiga, saudava a exposição da Academia onde há muito, segundo afirmava, não via provas de valor como as que então eram representadas pelos finalistas Henrique Franco (1883-1961) ou Alfredo Miguéis (1883-1943) e, sobretudo, por Dordio Gomes (1890-1976) ${ }^{2}$ que era, na sua opinião, um artista de valor e de técnica já segura (República, 25 de Março de 1911). Henrique Franco era premiado como pensionista de Estado com Bom Samaritano; e Dordio, discípulo de Veloso Salgado, com a pintura de História Jesus aplacando as águas, ganhava o Prémio Lupi e a pensão Walmor para Paris. Para José de Figueiredo era uma "exposição notável" (República, 25 de Março de 1911). Mas José de Figueiredo não mencionava nem Gabriel Rendas, ali expositor, que apresentava uma paisagem animalista, nem o malogrado Ricardo Ruivo, discípulo de Columbano, falecido entretanto em Paris, e um aluno mais velho, o pintor Adriano Sousa Lopes (1879-1944), referidos na Ilustração Portuguesa em 3 de Abril de 1911 ( $n^{\circ} 267$, pp. 423-425).

Das obras enviadas de Paris pelos pensionistas, a atenção do historiador voltava-se sobretudo para a estátua da "República" e para o baixo-relevo A Surpresa de Dion de Francisco Franco (1885-1955), o futuro autor da estátua a Gonçalves Zarco que também era elogiado pelas "influências" francesas de Rodin, e, para um estudo em pastel, da autoria de José Campas (1888-1971), ${ }^{3}$ intitulado La Femme qui se chauffe (1887), que este fizera do pintor e gravador francês Paul-Albert Besnard (1849-1934) e que o referido artigo da Ilustração Portuguesa reproduziu nas suas páginas, comentando a sensualidade latente e a nudez que pretendia ser ingénua mas que via como "gloriosa". Mas é a SantaRita que José de Figueiredo dedica grande parte da crítica da exposição, chegando mesmo a interrogar-se porque razão o jovem escolhera aquela pintura. É que, para ele, uma cópia de Manet só podia ser “inferior". Não pelo facto de ser uma cópia, pois não era este o seu principal reparo. É que copiar Manet era impossível. E se era impossível, era inferior. E explicava que a superioridade dessa tela, que representou na época em que foi feita uma verdadeira revolução artística, lhe vinha da sua luminosidade, sendo essa ainda a única qualidade que a impunha aos que com ela se defrontam. E, se assim era, perguntava "para

\footnotetext{
2 Dórdio Gomes, formado em Pintura de História, foi pensionista do Estado em Paris. Tal como a SantaRita, a bolsa foi-lhe suspensa por João Chagas, na mesma altura. Regressaria a Paris em 1921, depois de lhe ser de novo atribuída a bolsa suspensa. Entre 1933 e 1960, leccionou na Escola de Belas-Artes do Porto. Foi prémio Columbano (1938) e António Carneiro (1945) e obteve o prémio de pintura na I Exposição de Artes Plásticas da Fundação Calouste Gulbenkian.

${ }^{3}$ Pintor naturalista, discípulo de Carlos Reis. Foi Prémio Anunciação em 1905 e 1906. Em Paris frequentou a Academia Julian e concluiu o Curso da École Nationale et Spéciale des Beaux-Arts. Foi aluno de JeanPaul Laurens, Léon Bonnat, Raphaël Collin e Jobbe Duval. Expôs em Paris em 1910, 1911, 1923 e 1928. Obteve a $1^{\mathrm{a}}$ medalha em pintura na S.N.B.A. Ganhou medalhas na Exposição Panamá-Pacífico, nas Exposições do Rio de Janeiro e Barcelona. Foi crítico de arte na imprensa portuguesa e delegado do Governo Português na Exposição Internacional de 1937. Foi também bibliófilo, professor de português e director das Escolas Técnicas de Lagos e Abrantes. Em 1966, na Galeria Diário de Notícias em Lisboa, realizou-se uma retrospectiva da sua obra.
} 
que se deu então à canseira de a copiar o sr. Santa-Rita?" Segundo ele, devia ter ocorrido ao pintor que o quadro de Manet, tendo o seu valor no momento em que veio a lume, e sendo representativo para a arte do seu país, "nada vem entretanto ensinar-nos, servindo antes para desnortear os que não estejam em condições de bem o apreciar" (República, 25 de Março de 1911).

José de Figueiredo apreciava, sim, a opção do jovem José Campas que escolhera fazer cópias das pinturas de Paul-Albert Besnard (1849-1934), que fora «Prix de Rome», em 1874. Besnard definia-se por uma técnica impressionista "amaneirada". Os seus nus tinham aparência de odaliscas sensuais, mas, para o historiador e crítico, o contacto com o trabalho desse pintor só podia ser proveitoso, na medida em que Besnard conhecia "como ninguém a teoria da divisão dos tons, a das cores complementares e a da dissociação cromática em que tão alto se afirmaram, segundo ele, Monet, Sisley e Pissarro, acabando por superar os pintores impressionistas" (República, 25 de Março de 1911).

No jornal Novidades, Higino de Mendonça, um "medíocre pintor amador" (França, 1974, p. 29), que no mesmo jornal apelidara de "malucos" os expositores livres, escrevia que encontrava uma disciplina escolar correcta e uma verdadeira orientação artística por parte dos professores tanto no que dizia respeito aos estudos de paisagem como aos de pintura histórica, escultura e arquitectura. Contudo, ao comentar os estudos do nu, omitiria os autores dessas representações, e incentivaria à apreensão dos trabalhos por atentado ao pudor. Dizia ele que a direcção da Academia, sabendo que aquela exposição podia "levar ali muitas senhoras e meninas, deveria ter uma certa reserva nos estudos do nú, que representam modelos que estamos certos o sr. Governador civil do distrito não consentiria expostos na vitrine d'um estabelecimento qualquer". E acrescentava que se isto assim era, não parecia razoável que se consentisse esta exposição de pintura (Novidades, 25.03.1911).

Para o jornalista do Novidades, parece estar em causa valores morais, mas José de Figueiredo, aparentemente, não parecia escandalizado. Desaprovava a iniciativa de SantaRita que escolhera copiar Manet, tal como fizera em princípios do século ao reprovar António Carneiro por este se guiar demasiado por Puvis de Chavannes (Figueiredo, 1901, pp. 118-119). Podemos interrogar-nos se José de Figueiredo ao falar de luminosidade não estaria a considerar Manet do ponto de vista do impressionismo. Porém, o realismo histórico da pintura de Manet afasta-se da pintura de "ar-livre" ou "d'après-nature" dos naturalistas e mesmo dos impressionistas, segundo o historiador Bernardo Pinto de Almeida (1996, p. 127), embora se possa aproximar de um realismo perceptual. Era um "pintar 'd'après peinture"” (Almeida, 1996, p. 127) numa relação constante com o passado e com a tradição, mas rompendo ao mesmo tempo com eles.

\section{Olympia, um novo regime da imagem no contexto do ensino das Belas- Artes em Portugal}

Olympia, dialogava com uma dimensão temporal e com uma tradição de renovada discursividade que produzia novos sentidos, trazendo uma modernidade estética desconhecida do academismo português. Santa-Rita não se preocupara por certo com as regras da Academia, da beleza ou da moral. Como afirma Bernardo Pinto de Almeida, se pintar se tornara um fim em si e não uma obrigação para com um modelo, tratava-se de continuar a investigar as possibilidades de desenvolvimento do discurso pictural e da sua especificidade, num diálogo com as formas tal como os mestres do passado o tinham enunciado, fundando a partir desse diálogo um novo tipo de relação com a História (Almeida, 1996, p. 128). 
Esse tipo de discursividade era afinal, segundo um modelo de autonomia estética, um novo entendimento do vocabulário formal e estava de acordo com uma linguagem em transformação na época. Por essa razão, este autor diria que é isso que faz com que Olympia se torne da ordem de um novo "regime de enunciação da imagem" (1996, pp. 121-131).

Esse novo regime da imagem era também um novo ponto de partida para o seu trabalho pictórico. Santa-Rita tinha escolhido, nada mais, nada menos, do que a obra fundadora da modernidade em pintura. Que pintura poderia constituir melhor exemplo contra o academismo da Escola de Belas Artes de Lisboa?

O posicionamento estético da sua decisão merece que revisitemos não só a história de Olympia como as fontes que Manet nela parece citar. Do mesmo modo, colocamos a questão de saber porque razão Santa-Rita escolheu esta e não outra pintura e o que é que dela recebeu para a sua própria obra?

Não sabemos o que o jovem pintor encontrou ou pensou sobre a Olympia de Manet. Podemos, todavia, interrogar a cópia que nos deixou, muito semelhante ao original. Esse trabalho académico deixa vislumbrar uma homenagem ao mestre francês e, simultaneamente, talvez uma crítica irónica ao método que desde sempre lhe tinha sido imposto como aprendizagem na Academia portuguesa.

Além de podermos inquirir essa pintura que se encontra lamentavelmente "esquecida" na Academia de Belas Artes de Lisboa, iremos tentar estabelecer, através do contexto parisiense em que viveu, uma aproximação a este universo estético.

Olympia era na época um quadro consagrado. Em exposição no Museu do Louvre desde 1907, foi oferecida pelo pintor Claude Monet ao Estado francês depois de comprada em subscrição pública. Em finais de 1910, em Londres, o pintor e crítico de arte Roger Fry (1866-1934) ${ }^{4}$ organizava, em Novembro de 1910, uma grande mostra da obra de Manet nas Grafton Galleries, sob o título Manet and the Post-Impressionists. O exito e o choque do público inglês foram grandes. Virgínia Woolf, depois de ver as pinturas de Manet, Matisse e Van Gogh, teria afirmado que o género humano mudara depois dessa exposição. Seguramente, a ressonância fizera-se ouvir em Paris e não teria passado despercebida à curiosidade de Santa-Rita. Também acreditamos que poderia ter tido consequências estéticas nas suas ideias, por aquilo que lhe permitiu reflectir.

Não se trata de compreender o olhar de Santa-Rita sobre Manet, tal como será impossível reencontrar o olhar de Manet sobre Tiziano. Daniel Arasse diz-nos que podemos, contudo, enquanto historiadores, tentar aproximar a história da pintura do enviesamento do olhar dos pintores sobre a pintura, pois são os artistas que fazem a história da arte fora das próprias categorias da história da arte (Arasse, 2004, p. 161).

\section{O debate à volta de Olympia}

Olhamos para Olympia e vemos o espaço de um interior construído em dois planos. No primeiro plano encontra-se o corpo de Olympia, uma mulher nua, reclinado numa cama, que olha fixamente para o espectador. Um gato preto está a seus pés. No segundo plano, o fundo mergulha na obscuridade de onde sai a empregada negra que traz na mão um ramo de flores, provavelmente oferecido por um cliente com quem passou a noite ou que

\footnotetext{
${ }^{4}$ Roger Fry foi o principal responsável pelas exposições em Londres onde se apresentou pela primeira vez a arte moderna. Fry cunhou o termo "pós-impressionismo", em 1910, na primeira dessas exposições Manet and Post-Impressionism. Dois anos mais tarde realizaria uma Second Post-Impressionist Exibition. Figura influente no mundo artístico, deve-se-lhe a ele e a Clive Bell, de quem foi amigo, a ênfase nas propriedades formais das obras, ficando na história da arte ligado ao que se veio a designar de "formalismo".
} 
a espera na sala contígua. Mas esta é uma descrição simples que faz alusão a uma prostituta de que o nome Olympia, na época, era o nome de guerra.

É ponto assente que a fonte mais evidente de Olympia é a Vénus de Urbino de Tiziano (1538), embora se aceite outras igualmente admissíveis como La Maja Desnuda de Francisco de Goya (c.1797-1800) e até Ingres. ${ }^{5}$ Daniel Arasse dedica grande atenção à questão, sublinhando a filiação directa, mais do que qualquer outra, dessa procedência clássica em relação a Tiziano. ${ }^{6}$ Pintada trezentos anos antes, ela foi o ponto de partida directo para a Olympia. A Vénus de Urbino é um nu sensual que representa a deusa do amor, tema explorado desde sempre por inúmeros pintores. Na primeira metade do século XIX, esse tipo de pintura tornara-se muito popular em França sendo vista como o exemplo de uma arte dramática cheia de cor e pictoricamente apelativa aos sentidos (Reff, 1976, p. 49). Courbet foi um dos que citou nas suas obras as Vénus de formas voluptuosas de Giorgione (c. 1477-1510) e Tiziano (c. 1473-1490) (Reff, 1976, p. 52). No Salon de 1863, o ano de realização de Olympia, mostraram-se três versões do Nascimento de Vénus, incluindo uma de Alexandre Cabanel (1823-1889), que foi a mais aclamada (Reff, 1976, p. 53). Estas obras, enquanto citação do nu clássico, eram vistas como pinturas da pele feminina cuja nudez era sublimada através de tons impossíveis que se aproximavam de um conceito de beleza eterna que era um modelo ideal. Para Manet, a figura da Vénus de Urbino era também um modelo ideal de representação. Porém, o pintor não seguiu a concepção dos artistas da Renascença, mas sim o equivalente de uma Vénus da sociedade em que vivia. Olympia era o retrato moderno de Victorine de Meurant, ${ }^{7}$ seu modelo, a figura de um corpo magro retirado da realidade. De flor vermelha no cabelo, uma bracelete no braço, os brincos e os pés calçados com umas elegantes chinelas, Victorine era simultaneamente um corpo suspenso e tenso, de olhar pasmado para um potencial espectador. Manet adopta uma das mais familiares convenções da pintura erótica e servese das fotografias eróticas suas contemporâneas ou até de outros registos de arte popular do século XIX como litografias eróticas do período romântico e as ilustrações e romances do período realista, alargando por consequência o contexto cultural em que a pintura deve ser compreendida (Reff, 1976, p. 29).

Na revisitação do passado que Manet citava ao traduzi-lo no realismo do presente, o pintor criava um "realismo histórico" traduzido na figura de uma alegoria. Tinha sido também o caso de Le Déjeuner sur L'Herbe (1863). Ambas as pinturas são documentos da vida da sociedade da sua época e registos eróticos que formavam uma parte importante das representações visuais da vida social e urbana do Paris dessa época. ${ }^{8} \mathrm{O}$ realismo de

\footnotetext{
${ }^{5}$ Edward Lucie-Smith (1993 [1ª ed. 1971], pp. 134, 137), aponta também a Vénus Sleeping de Giorgione (c. 1510), e mesmo a Odalisque with a Slave (1842) de Ingres. Théodore Reff aponta inúmeras fontes pictóricas e até literárias como Giorgione, La Maja Desnuda (c. 1797-1800) de Francisco de Goya; Mena Marques (2003), no catálogo Manet no Prado, sublinha Velásquez; Daniel Arrasse e Michael Fried, autores que seguimos, optam pela Vénus de Urbino de Tiziano.

${ }^{6}$ Segundo Arasse, Tiziano faz nesse seu primeiro nu uma operação teórica do nascimento do nu feminino, bem como a construção de um esquema espacial, de tal modo que uma linha vertical divide o quadro e o corpo da Vénus precisamente na zona da mão em cima do sexo. Em Olympia vemos esta linha presente, mas Manet desloca-a ligeiramente para a direita (Arasse, 2004, p. 165).

${ }^{7}$ Victorine Meurent foi a modelo mais importante de Manet na década de 1860. Posou para Déjeuner sur l' Herbe, Olympia, Mlle. V.... en traje de espada, La Cantante callejera, La joven com el loro e na década seguinte para El Ferrocarril. Foi modelo profissional e o seu nome aparece no atelier de Couture em 1862. Também se dedicou à pintura. Expôs no Salon de 1876 um auto-retrato e de novo em 1879. Foi também modelo de Alfred Stevens. A sua vida ilustra a liberdade e a emancipação feminina no Paris do século XIX. ${ }^{8}$ Por exemplo, os nus de Courbet, de Edgar Degas, Toulouse-Lautrec e Constatin Guys que nos deixaram imensos estudos e desenhos. Também os pintores académicos, combinando fórmulas de aparente respeitabilidade com falsa inocência, pintaram exemplos eróticos para apreciação do elemento masculino
} 
Olympia nascera, por um lado, da visita de Manet aos museus e do estudo e meditação das pinturas do passado que depois o pintor associava ao estudo actualizado do seu presente.

Em Portugal, o realismo durante o século XIX atravessou sem consequências o naturalismo nas artes plásticas. Esse naturalismo idealizava ainda a natureza num romantismo sentimental. O que Santa-Rita via em Olympia era essa presença que ia da indiferença à beleza, só comparável a uma natureza-morta, sem assunto ou significado (Bataille, 1955), a destruição da subjectividade, a substituição da representação pela imagem, da tradição pela moda e pelo moderno, da deusa pela mulher, da beleza pela carne. O inabitual realismo do modelo, que se constatava estar despido, contrastava com os corpos nus idealizados das deusas, ninfas e odaliscas. O público habituara-se a olhar "carnes" idealizadas, artificiosamente pintadas, em tons nacarados que fixavam uma beleza que se tinha tornado um protótipo banalizado. Sair desse código tornava-se estranhamente abusivo. Na época, foi caricaturada sarcasticamente, ridicularizou-se a excessiva magreza do modelo, a empregada negra, o gato tomado como elemento simbólico sexual, diabólico e agressivo. Olympia foi aceite pelo júri no Salon de 1865, mas a violência e a reacção do público foram tais que foi necessário a guarda do Salon para a proteger e repôr a ordem. As críticas trocistas da imprensa investiram contra os aspectos mais obviamente humanos de Olympia como a "pele amarelada do estômago" 9 ou, como referiu Téophile Gautier, a cor suja da pele e o modelado inexistente do corpo, pois a figura não tinha ossos e músculos (Gautier, citado por Reff, 1976, p. 18). Havia, assim, uma incongruência entre o hábito de ver uma odalisca e aquele modelo real que perturbava.

Habitualmente, o público via um corpo apresentado como uma superfície artificialmente lisa e modelada que idealizava uma beleza eterna e mítica. Olympia era pelo contrário um corpo pintado com tintas, cuja pele se aproximava dos tons coloridos e verdadeiros, com as suas manchas e irregularidades, o corpo de uma mulher real. As pinceladas fortes e sombrias, tão criticadas, mostravam que se tratava de uma mulher despida e desclassificada socialmente. Não era só formalmente, mas era também o assunto tratado, uma mulher e modelo conhecida do seu tempo, que tornava Olympia chocante e provocadora. A modelo e amante de Manet olhava directamente e sem vergonha nos olhos do espectador e confrontava-o com o seu desejo. Para Edward LucieSmith esta mulher está alerta e olha para fora da tela de um modo que deixa claro que não se submete a nenhum homem (1993, p.135).

Émile Zola, de quem Manet haveria de pintar um célebre retrato em 1868, foi aquele que, segundo alguns autores, fez a crítica mais atenta à hipocrisia da sua época. Zola escreveria que Olympia tinha a "grave culpa" de se parecer com jovens senhoras e não com os nus pulverizados de pó de Cabanel (Zola, 1866, citado por Reff, 1976, p. 21).

Todavia, Zola foi evoluindo para uma atitude mais naturalista do que realista. Passou a concentrar-se mais nas qualidades formais e a enaltecer os tons e a luminosidade, daquilo a que chamou "a pintura analítica" de Manet (Reff, 1976, pp. 21-26). Esta posição viria mesmo a ter uma enorme importância na crítica futura, sobretudo no suporte a uma visão formalista, quer durante os anos 20 e 30 do século XX, como na emergência das visões puristas e neo-clássicas da arte do pós-guerra. Esse debate estendeu-se por todo

onde a mulher aparece sujeita à escravidão ou à mercê das orgias masculinas: Thomas Couture, The Romans of the Decadence, (1847), ou Jean Léon Gérôme, The Slave Market; de Edwin Long, The Babylonian Slave Market, 1875, ou Max Slevogt, The Victor (Prizes of War), 1912.

${ }^{9}$ «What is this Odalisque with a yellow stomach, a base model picked up I Know note where, who represents Olympia? Olympia? What Olympia?» J. Claretie, (L'Artiste, 15 Maio, 186), citado por Reff, 1976, p. 18. 
o século XX. Para Lionello Venturi (1950), por exemplo, Manet, introduziria com Olympia o princípio da autonomia na visão da arte, que toda a arte moderna utilizou como ponto de partida e bandeira. E, ao contrário de Paul Valéry que, nos anos 30, falava da "fria e desnudada Olympia, esse monstro de sensualidade banal", Georges Bataille, em 1955, afirmou terminantemente que o quadro só fazia sentido na medida em que Manet afastou dele o sentido literal que Valéry lhe atribuíra (Battaile, 1955, citado por Reff, 1976, p. 26).

Quando Manet expôs pela primeira vez Olympia, acompanhava-a uma outra pintura Jesus mocked by the soldiers (ou Christ Scourege) (Reff, 1976, pp. 45-46), um quadro muito diferente no tema, mas que se apresentava como uma espécie de contrabalanço com um nu masculino. ${ }^{10} \mathrm{O}$ pintor já tinha ensaiado pouco antes outras obras com o tema de Cristo, ${ }^{11}$ incorporando fontes antigas a modelos do natural como era seu costume e por essa razão, foi apelidado de pasticheur (Mena Marques, 2003, p. 234). ${ }^{12}$ Os ataques centravam-se no modo como o pintor deveria tratar pictoricamente o retrato de alguém que representava "o amor divino" e "a pureza absoluta" e, por essa razão, censuravamlhe o "desprezo" pela técnica pictórica que não sabia representar o carácter sagrado do corpo divino. As sombras e as gradações de luz faziam desse corpo "um cadáver por lavar" ou um "miserável mineiro saído de uma mina de carvão". A expressão pictórica de Manet era vista então como a ilustração das ideias do racionalista Ernest Renan, Vie de Jésus, publicado justamente em 1863, que oferece a imagem de um Cristo puramente mortal e humano, cuja divinização era o resultado de questões históricas concretas (Mena Marques, 2003, p. 234). As críticas ao Cristo, que Manet expôs junto com Olympia, foram portanto igualmente ferozes e uniram-se no tom. Eram "a nauseabunda Olympia e o horrível Ecce Homo de M. Manet. Quando a arte caiu tão baixo não merece sequer uma repreensão". Justamente, o amigo de Manet, Edmond Bazille, em 1884, referia como o público nessa época se habituara a uma "natureza embelezada (...). O Império havia idealizado os gostos, e odiava ver as coisas tal como são" (Mena Marques, 2003, p. 234).

Esta referência a um Ecce Homo não é uma coincidência. Ela lembra que um dia Santa-Rita haveria precisamente de se interessar também por essa figura, juntamente com Almada Negreiros e Amadeo de Souza-Cardoso.

\section{O quadro como um palco e a problemática do corpo e do rosto}

Em Paris, em 1863, o público confrontara-se com um novo olhar sobre o corpo e uma nova maneira de o pintar. A figura idealizada dera lugar a uma mulher real que se deixara retratar despida. Era o retrato de um rosto e de um corpo nu, com as suas imperfeições, as suas cores, as suas sombras, o retrato de Victorine Meurent, do rosto e do corpo caracterizados.

Também não era a primeira vez que Manet fazia esta justaposição de géneros ou subgéneros pictóricos: retrato, nu e pintura de género, neste caso; ou paisagem, pintura de história, retrato e nu e cena de género que se fundem como em Le Déjeuner sur L'Herbe (1862-1863), uma pintura que o júri do Salon rejeitou em 1863, talvez escandalizado pela

\footnotetext{
${ }^{10}$ Não era a primeira vez que isso acontecia. No Salon anterior Manet tinha apresentado, ao lado de Le Déjeuner sur l'Herbe, o tema da morte, Incident in a Bull Ring e Dead Christ with Angels. Ver Theodore Reff, p. 45.

${ }^{11}$ Com The Dead Christ and Angels que expusera em 1864.

12 Por ter fortes analogias com Anunciación de El Greco, mas sobretudo com Christo Death de Andrea del Sarto, fresco do cenáculo de San Salvi, em Florença, que Manet visitou em 1857.
} 
sugestão erótica das três figuras pintadas numa paisagem imaginária e que Manet mostrou no Salon des Réfusés organizado por si próprio.

A estratégia de que fala Arasse é que a pintura confronta ou faz frente ao espectador, quando o corpo ocupa a superfície, ou seja, o primeiro plano da tela. O olhar do espectador como que é obrigado a mergulhar no corpo que se impõe ao olhar. Nesse momento, este desloca-se do rosto ou do olhar desafiador de Olympia para esse corpo paisagem. Anos antes, Manet tinha realizado uma minúscula cópia dessa pintura. Não que ela seja a explicação para Olympia, mas porque a sua justificação se encontra, segundo Daniel Arasse, escondida no próprio quadro de Tiziano. Nesta ideia, Arasse afirma seguir as ideias de Michael Fried sobre a Olympia de Manet. Ele encontra no modo como Tiziano colocou o corpo de Vénus entre dois espaços e no modo como construiu as figuras e a perspectiva geométrica, dando ao espectador uma posição precisa no quadro, isto é, frente a ele, algo que Manet vem também a usar, e que Michael Fried descobre que é esse face a face com o espectador. Esse aspecto, segundo Arasse, vai ser próprio da modernidade (Arasse, 2004, p. 164) ${ }^{13}$ e dará origem à utilização do quadro como um palco.

Que faz, pois, esta mulher deitada à nossa frente na superfície do quadro? Ela olhanos. Olympia tinha deste modo suscitado uma reacção violenta do público. Ainda hoje, objecto de debates apaixonados, continua a ser um ícone venerado da cultura. Ela parece forçar-nos a assumir que estamos na mesma sala (Hamilton, 1954, citado por Reff, 1976, pp. 16-17), obrigando-nos a desviar o olhos para o seu corpo cuja força se impõe e transforma sobretudo no retrato de um corpo.

Esta relação performativa que se estabelece pela primeira vez entre o quadro e o olhar do espectador foi assinalada por Michael Fried (1994, pp. 1-36). Este autor, nos seus estudos sobre a pintura do século XVII e sobre Denis Diderot, detectou na pintura francesa uma tradição anti-teatral até cerca de 1860. No centro dessa tradição encontravase a teorização feita por Diderot, segundo o qual as figuras numa pintura deveriam ser representadas ou actuar como se o espectador não existisse. O pintor tinha de estabelecer a ilusão metafísica de que o espectador não estava para lá do quadro. E isso conseguia-se através das acções dos figurantes que eram representadas como se estivessem absorvidos em todos os aspectos das suas actividades, fosse nas tarefas quotidianas, fosse na expressão de sentimentos ou estados de espírito. Isto fazia com que a negação do espectador acabasse por ser uma convenção essencial (Fried, 1994, p. 6). Ora o que Manet vai fazer é inverter essa relação trazendo ao encontro da pintura aquele que a olha e, nessa medida, a subjectividade desse olhar, levando-nos a compreender que também o corpo nos olha. Então podemos interrogar, como o fez Georges Didi-Huberman (1991), o retrato como um "nó antropológico", pois "onde começa o retrato e quando se ausenta o rosto"? Segundo ele, a questão do retrato não deve ser colocada enquanto género, mas enquanto caixa vazia - um lugar simbólico. E avança a hipótese de que o retrato nasce, sim, com a morte de um ente querido. É essa a explicação para que o homem pré-histórico faça a gestão da perda, transformando os crânios em caixas abertas e esburacadas que funcionam simbolicamente. Em segundo lugar, o autor afirma que a evidência de um rosto que se manifesta paradoxalmente nessa caixa vazia é um lugar, o lugar de um rosto ausente, que fornece a resposta à questão do retrato. Ora se o rosto se ausenta para em seu lugar se

\footnotetext{
${ }^{13}$ Daniel Arasse refere que deve esta descoberta a Michael Fried e ao seu livro The Facingness of Painting. Segundo o autor, o ramo de flores da serva negra faz tanto face ao espectador como o olhar de Olympia. Deste modo, diz ter compreendido o que Manet viu na Vénus de Urbino, e porque é que ele foi buscar este nu, que não é o mais sumptuoso de Tiziano, mas é sem dúvida o mais teórico. Pediram a Tiziano para pintar uma mulher nua, o título da encomenda era La Donna Nuda, e ele pintou uma mulher nua, mas o lugar desta mulher nua é a própria pintura.
} 
sobrepor ou deslocar para o corpo é porque a função do retrato, que até aí era a de nos dar a identidade de alguém, deixou de cumprir a sua função.

Esta transformação na percepção do Outro e em particular do rosto do Outro, que também implica uma transformação na percepção de si próprio e que devia, segundo o retrato clássico, estar focalizado na representação do rosto, sofria aqui uma deslocação para o corpo. Olympia tornara-se um corpo, somente a presença de um corpo a ser olhado.

$\mathrm{O}$ facto é que Olympia inaugurava o encontro entre o rosto e o corpo, assim como a própria ideia de que ambos se podem equivaler e substituir um ao outro. $\mathrm{O}$ "princípio de fragmentação" que separava o rosto do corpo, quer no plano simbólico quer no das representações, e que vinha acontecendo, desde o séc. XVII, estilhaçava o corpo funcional, operativo, através da erotização ou do "devir-carne do corpo" (Almeida, 2013).

Certamente Santa-Rita teria compreendido algo que fazia já parte das fotografias eróticas desse tempo e que existia também nesta pintura. $\mathrm{O}$ modo como se estruturava o tempo e a sua duração em vários instantes, numa sucessão, na relação do espectador ao olhar Olympia parecia conter a ideia de instante fotográfico. Mas também de abandono de uma profundidade perspectivista de tal modo que, na captação do real, o público estranhamente ficaria incomodado pela sua veracidade, uma veracidade que só a fotografia era capaz de dar até aí. Mas o que é que distinguia este retrato, o retrato fotográfico, do retrato clássico pictórico?

O retrato clássico define-se pela sua identidade com o retratado. Identidade que está focada na representação do rosto. Por essa razão, o retrato exprimia a sua «alma» ou "personalidade", isto é, jogando-se no rosto a semelhança do retratado. Era a cabeça e o rosto que definiam a unidade da totalidade do indivíduo. No rosto concentrava-se o que pertencia à outra parte - o corpo. Mas, se a cabeça aparecia como metonímia do corpo inteiro, ela também reforçava a separação das partes. Olympia foi, quanto a nós, o exemplo maior da desintegração dessa unidade corporal, da cabeça e do rosto, e da abertura à "evidenciação da carne na arte" (Almeida, 2013).

\section{Santa-Rita e o novo olhar sobre o corpo}

Mesmo sabendo que nunca teremos respostas, talvez possamos aproximar-nos da "verdade" de Santa-Rita ao afirmar que, em Paris, ele quis "ajustar contas com o seu tempo, tomar posição a respeito do presente" (Agamben, 2009, pp. 19-20). ${ }^{14}$ Essa "intempestividade" fê-lo ser "contemporâneo" de Manet e do seu próprio tempo, intempestivamente é certo, mas numa relação singular na conformidade de alguém que se deu conta da atemporalidade em que vivia a arte do próprio país. Santa-Rita viria a pintar um quadro intitulado Orpheu nos Infernos, ${ }^{15}$ onde ironizou, mordaz, a figura do seu academismo, colocando Veloso Salgado (1864-1945), seu professor e pintor de história, retratista mundano de aparato, que o fora da monarquia e que o seria da república, como personagem no meio do inferno.

14 Giorgio Agamben, em "O que é o Contemporâneo", interroga-se de quem e de quê somos contemporâneos e o que é que isso significa. Esta interrogação surge-lhe a partir do pensamento de Nietzsche em Considerações Intempestivas (1874), onde o filósofo procura compreender como uma pretensão à actualidade é também um desfasamento e, nessa medida, pode ser um ajuste de contas, significando também que esse posicionamento parte de alguém que se consegue distanciar melhor do seu tempo para ver melhor.

${ }^{15}$ Seria reproduzido em Portugal Futurista publicado em 1917 (4ª edição fac-similada, Lisboa: Contexto, 1990). A datação de 1903 é uma provável blague intencionalmente irónica. A pintura será talvez desse ano de 1917 ou um pouco anterior.

Revista 2i, Vol. 1, N. ${ }^{\circ}$ Especial, 2019, pp. 53-65. elSSN 2184-7010 
Olympia era, portanto, uma imagem moderna, a imagem de uma mulher e de um Paris do século XIX durante o $2^{\circ}$ Império; ou mesmo um quadro de costumes da vida moderna de uma cidade, no sentido do "urbano", que lhe dava Charles Baudelaire em O Pintor da Vida Moderna.

Ao realizar a sua cópia, Santa-Rita revisitava a tradição clássica, como o fizera Manet, para proclamar uma modernidade que não existia no seu país e proclamava-o a seu modo homenageando o pintor francês. Essa modernidade era também a liberdade do artista, isto é, o fazer uma arte de acordo com a sua época, tanto na temática quanto na forma. Assim, a liberdade reivindicada pela cópia de Olympia re-interrogava o retrato, "arruinava-o" enquanto imagem do rosto, deslocando-o e inscrevendo-o sobre o corpo. Por outro lado, não deixava, igualmente, de afrontar o sentido de propriedade que um homem tem para com uma mulher, ou que os professores ou académicos, seus professores, tinham como detentores da verdade da pintura.

\section{REFERÊNCIAS}

Agamben, G. (2009). Nudez. Lisboa: Relógio d’Água.

Almeida, B. P. (1996). O Plano de imagem, espaço da representação e lugar do espectador. Lisboa: Assírio \& Alvim.

(2013). Do corpo à carne: Apontamentos de um trajecto. In J. Gil \& A. Godinho (coords.), II Encontros de Estética: Que corpo na arte. Lisboa: FCSH/Nova e Instituto Francês de Portugal.

Bataille, G. (1955). Manet. New York: Albert Skira.

Didi-Huberman, G. (1991, verão). Le visage et la terre. Art Studio (Le Portrait Contemporain), (21).

França, J.-A. (1974). História da arte em Portugal no século XX (1911-1961). Lisboa: Livraria Bertrand.

(1990). História da arte em Portugal no século XIX (vol. II). Lisboa: Livraria Bertrand.

(1991). O modernismo na arte portuguesa. Lisboa: ICALP.

Figueiredo, J. (1901). Portugal na Exposição de Paris. Lisboa: Livraria Moderna.

[Figueiredo, J.]. (1911, março 25). Bellas Artes. Uma exposição interessante. Trabalhos dos alumnos da Academia de Bellas-Artes - Francisco e Henrique Franco - A exposição Ruivo e as cópias de Campas. República.

Freitas, E. (1913, março 1). O Cubismo nacional. Guilherme de Santa-Rita. Teatro, p. 4.

Fried, M. (1994, autumn). Between realisms: from Derrida to Manet. Critical Inquiry, 21 (1), 136.

Jouannais, J.-Y. (2009). Artistes sans oeuvres I would prefer not to. Paris: Editions Gallimard. 
Lucie-Smith, E. (1993). Sexuality in Western art [1971]. London: Thames and Hudson.

M., H. [Mendonça, Higino de]. (1911, março 25). Artistas e ateliers. Exposição de pintura Trabalhos dos alunos da Escola de Bellas Artes. Novidades.

Macedo, D. (1953, novembro). Notas de Arte. Revivendo. Ocidente, XLV (187).

Negreiros, J. A. (1965). Orpheu 1915-1965. Lisboa: Edições Ática.

Portugal Futurista [1917] (1990). Lisboa: Contexto.

Reff, T. (1976). Manet: Olympia. London: Allen Lane Penguin Books Ltd.

(A autora segue a antiga ortografia.) 
